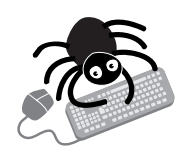

Please visit the Heart website (www.heartinl.com) for links to these articles many to full text.

\section{Ischaemic heart disease}

Wouldn't you want primary angioplasty for your MI? - The evidence for the benefits of primary angioplasty over thrombolysis is strengthened further by the latest meta-analysis. Primary angioplasty was better than thrombolytic treatment at reducing overall short term death $(7 \% \vee 9 \% ; p=0.0002)$, non-fatal reinfarction $(3 \%$ v $7 \% ; p<0.0001)$, stroke $(1 \% v 2 \% ; p=0.0004)$, and the combined end point of death, non-fatal reinfarction, and stroke $(8 \% \vee 14 \% ; p<0.0001)$. The results seen with primary angioplasty remained better than those seen with thrombolytic treatment during long term follow up, and were independent of both the type of thrombolytic agent used, and whether or not the patient was transferred for primary angioplasty.

$\Delta$ Keeley EC, Boura JA, Grines CL. Primary angioplasty versus intravenous thrombolytic therapy for acute myocardial infarction: a quantitative review of 23 randomised trials. Lancet 2003;361:13-20.

Trial shows statins do not produce benefit - After a host of trials suggesting statins lower coronary heart disease (CHD) risk in patients with normal cholesterol even if they have not had previous vascular events, the ALLHAT trial of 10355 patients suggests that $40 \mathrm{mg}$ of pravastatin in hypertensives with at least one additional risk factor gain no benefit. At year 4 , total cholesterol concentrations were reduced by $17 \%$ with pravastatin versus $8 \%$ with usual care; among the random sample who had low density lipoprotein (LDL) cholesterol concentrations assessed, levels were reduced by $28 \%$ with pravastatin versus $11 \%$ with usual care. All cause mortality was similar for the two groups (relative risk (RR) 0.99, 95\% confidence interval $(\mathrm{CI}) 0.89$ to $1.11 ; p=0.88)$, with six year mortality rates of $14.9 \%$ for pravastatin versus $15.3 \%$ with usual care. CHD event rates were not significantly different between the groups (RR 0.91, 95\% Cl 0.79 to $1.04 ; p=0.16$ ), with six year CHD event rates of $9.3 \%$ for pravastatin and $10.4 \%$ for usual care. Perhaps cholesterol concentrations were not lowered enough to detect a difference?

$\Delta$ The ALLHAT Officers and Coordinators for the ALLHAT Collaborative Research Group. Major outcomes in moderately hypercholesterolemic, hypertensive patients randomized to pravastatin vs usual care: the antihypertensive and lipid-lowering treatment to prevent heart attack trial (ALLHAT-LLT). JAMA 2002;288:2998-3007.

Shouldn't we be screening for insulin resistance? The metabolic syndrome, a concurrence of disturbed glucose and insulin metabolism, overweight and abdominal fat distribution, mild dyslipidaemia, and hypertension, is associated with subsequent development of type 2 diabetes mellitus and cardiovascular disease (CVD). In a cohort of 1209 Finnish men aged 42-60 years at baseline (1984 to 1989) who were initially without CVD, cancer, or diabetes, the prevalence of the metabolic syndrome ranged from 8.8-14.3\%, depending on the definition. Men with the metabolic syndrome, as defined by the NCEP, were $2.9(95 \% \mathrm{Cl} 1.2$ to 7.2$)$ to $4.2(95 \% \mathrm{Cl} 1.6$ to 10.8$)$ times more likely and, as defined by the World Health Organization, 2.9 $(95 \% \mathrm{Cl} 1.2$ to 6.8$)$ to $3.3(95 \% \mathrm{Cl} 1.4$ to 7.7$)$ times more likely to die of CHD after adjustment for conventional cardiovascular risk factors. The metabolic syndrome as defined by the WHO was associated with $1.9(95 \% \mathrm{Cl} 1.2$ to 3.0$)$ to $2.1(95 \% \mathrm{Cl} 1.3$ to 3.3) times higher all cause mortality. Factor analysis using 13 variables associated with metabolic or cardiovascular risk yielded a metabolic syndrome factor that explained $18 \%$ of total variance.

A Lakka H-M, Laaksonen DE, Lakka TA, Niskanen LK, Kumpusalo E, Tuomilehto J, Salonen JT. The metabolic syndrome and total and cardiovascular disease mortality in middle-aged men. JAMA 2002;288:2709-16.

\section{Heart failure}

Slow leak of troponin in heart failure suggests worse prognosis - Mean (SD) concentrations of heart type fatty acid binding protein were greater in patients with New York Heart Association (NYHA) functional class III or IV heart failure 19.9 $(5.2) \mathrm{ng} / \mathrm{ml})$ than in patients with NYHA class II $(4.9$ (1.9) ng/ml; $p<0.0001)$. Detection of troponin $T(\geqslant 0.02 \mathrm{ng} / \mathrm{ml})$ was also more common in patients with worse heart failure $(81 \%(13 / 16)$ in class III or IV $v 43 \%(17 / 40)$ in class II; $p=0.02)$. Significant correlations were found between heart type fatty acid binding protein concentrations and plasma concentrations of A type natriuretic peptide $(r=0.45 ; p=0.0004)$, B type natriuretic peptide $(r=0.66 ; p<0.0001)$, and noradrenaline (norepinephrine) $(r=0.36 ; p=0.006)$. Heart type fatty acid binding protein and troponin T are markers of ongoing myocardial damage, and are associated with subsequent cardiac events in patients with chronic heart failure.

A Setsuta K, Seino Y, Ogawa T, Arao M, Miyatake Y, Takano T. Use of cytosolic and myofibril markers in the detection of ongoing myocardial damage in patients with chronic heart failure. Am J Med 2002;1 13:717-22.

\section{Hypertension}

Diuretics are as good as ACE inhibitors in the treatment of mild/moderate hypertension - Angiotensin converting enzyme (ACE) inhibitors have become popular as the drug of choice in patients at risk of ischaemic heart disease (IHD) who also have hypertension, on the basis of risk reduction data in the HOPE trial. The ALLHAT trial of over 30000 patients with mild/moderate hypertension and at least one risk factor for IHD suggests that chlorthalidone, amlodipine, and lisinopril all lowered blood pressure (from 146/84 to $135 / 75 \mathrm{~mm} \mathrm{Hg}$ ), with the diuretic slightly more effective than the other two. There was no difference in total mortality, CHD risk or risk of renal failure. The lisinopril arm had a higher risk of stroke (RR 1.15; $p=0.02$ ), and the diagnosis of congestive cardiac failure was also more common in the lisinopril (RR 1.19; $p<0.001$ ) and amlodipine arms (RR 1.38; $<<0.001$ ). In addition, diuretics are very cheap!

$\Delta$ The ALLHAT Officers and Coordinators for the ALLHAT Collaborative Research Group. Major outcomes in high-risk hypertensive patients randomized to angiotensin-converting enzyme inhibitor or calcium channel blocker vs diuretic: the antihypertensive and lipid-lowering treatment to prevent heart attack trial (ALLHAT). JAMA 2002;288:2981-97.

Blood pressure targets may need to be lowered again Information was obtained on each of one million adults with no previous vascular disease recorded at baseline in 61 prospective observational studies of blood pressure and mortality. During 12.7 million person-years at risk, there were about 56000 vascular deaths and 66000 other deaths at ages 40-89 years. Within each decade of age at death, the relative risk of vascular death associated with a given absolute difference in one blood pressure is about the same down to at least $115 / 75 \mathrm{~mm} \mathrm{Hg}$. At ages 40-69 years, each difference of $20 \mathrm{~mm} \mathrm{Hg}$ usual systolic blood pressure (or, approximately equivalently, $10 \mathrm{~mm} \mathrm{Hg}$ usual diastolic blood pressure) is associated with more than a twofold difference in the stroke death rate, and with twofold differences in the death rates from IHD and from other vascular causes. Pulse pressure is much less informative.

\ Prospective Studies Collaboration. Age-specific relevance of usual blood pressure to vascular mortality: a meta-analysis of individual data for one million adults in 61 prospective studies. Lancet 2002;360:1903-13. 


\section{General cardiology}

Anticoagulation, not sinus rhythm, is what patients with AF need - Two studies suggest that rate control may be as good as (if not better than) trying to maintain sinus rhythm in atrial fibrillation (AF). The AFFIRM trial of > 4000 patients found equivalent mortality rates (mortality at five years, $23.8 \%$ v $21.3 \%$, respectively; HR $1.15,95 \% \mathrm{Cl} 0.99$ to $1.34 ; \mathrm{p}=0.08$ ) but higher rates of hospitalisation and adverse drug reactions in the rhythm control arm. In a separate trial of 522 patients who had persistent AF after a previous electrical cardioversion, the end point of a composite of death from cardiovascular causes, heart failure, thromboembolic complications, bleeding, implantation of a pacemaker, and severe adverse effects of drugs was similar in rate control and rhythm control groups (17.2\% v $22.6 \%, p=n s)$. This was despite $39 \%$ rate of sinus rhythm in the rhythm control group versus $10 \%$ in the rate control group.

$\Delta$ The Atrial Fibrillation Follow-up Investigation of Rhythm Management (AFFIRM) Investigators. A comparison of rate control and rhythm control in patients with atrial fibrillation. N Engl J Med 2003;347: 1825-33.

A Van Gelder IC, Hagens VE, Bosker HA, Kingma JH, Kamp O, Kingma T, Said SA, Darmanata JI, Timmermans AJM, Tijssen JGP, Crijns HJGM, for the Rate Control versus Electrical Cardioversion for Persistent Atrial Fibrillation Study Group. A comparison of rate control and rhythm control in patients with recurrent persistent atrial fibrillation. N Engl J Med 2002:347: 1834-40.

Pulmonary artery catheters do not increase (or reduce) mortality on ITU - Previous work suggested that, far from improving management, pulmonary artery (PA) catheters might be associated with worse outcome. Of 3803 eligible patients aged $>60$ years, 1994 (52.4\%) underwent randomisation. Patients were due to undergo surgery with an expected stay on the intensive therapy unit (ITU). Without the use of a PA catheter $7.7 \%$ died in-hospital, as compared with $7.8 \%$ in whom a PA catheter was used. There was a higher rate of pulmonary embolism in the catheter group than in the standard care group ( 8 events $v 0$ events; $p=0.004)$. The survival rates at 6 at 12 months were identical. Perhaps PA catheters offer no advantage to the astute intensivist.

A Sandham JD, Hull RD, Brant RF, Knox L, Pineo GF, Doig CJ, Laporta DP, Viner S, Passerini L, Devitt H, Kirby A, Jacka M, for the Canadian Critical Care Clinical Trials Group. A randomized, controlled trial of the use of pulmonary-artery catheters in high-risk surgical patients. N Engl J Med 2003;348:5-14.

Dual chamber ICDs may do more harm than good - If implanting a defibrillator, perhaps dual chamber pacing should be included in case it is needed. Atrioventricular (AV) synchrony would seem important in patients with low ejection fractions. Having implanted dual chamber pacing ICDs, half the patients were programmed to use them at a rate of 70 beats $/ \mathrm{min}$, while the other group provided backup ventricular pacing at 40 beats/min. None of the patients actually had an indication for antibradycardia pacing. One year survival free of the composite end point (death, heart failure) was $83.9 \%$ for patients treated with VVI-40 compared with $73.3 \%$ for patients treated with DDDR-70 (relative hazard $1.61,95 \% \mathrm{Cl} 1.06$ to 2.44 ). Perhaps right atrial pacing is not physiological after all. A better move may be to provide ventricular resynchronisation with biventricular ICD implantation.

$\triangle$ The DAVID Trial Investigators. Dual-chamber pacing or ventricular backup pacing in patients with an implantable defibrillator: the dual chamber and VVI implantable defibrillator (DAVID) trial. JAMA 2002;288:31 15-23.

\section{Basic science}

Screening candidate genes to discover novel cardiac risk factors - Modern technology can allow the screening of a large number of polymorphisms simultaneously. Of 112 polymorphisms screened in a sample of 909 myocardial infarction (MI) patients, 19 with possible relevance to IHD were found. The rest of the population (2819 Japanese patients with $\mathrm{Ml}$ and 2242 unrelated controls) was then used to assess relative risk associated with these polymorphisms. Logistic regression analysis revealed that the risk of $\mathrm{Ml}$ was significantly associated with the C1019T polymorphism in the connexin 37 gene $(p<0.001)$ in men, and the $4 G-668 / 5 G$ polymorphism in the plasminogen activator inhibitor type 1 gene $(\mathrm{p}<0.001)$ and the 5A-1171/6A polymorphism in the stromelysin-1 gene $(p<0.001)$ in women. The hope is that these associations may lead to more insight into the pathophysiology of IHD, and so to novel treatments.

A Yamada $Y$, Izawa $H$, Ichihara S, Takatsu F, Ishihara $H$, Hirayama $H$, Sone T, Tanaka M, Yokota M. Prediction of the risk of myocardial infarction from polymorphisms in candidate genes. N Engl J Med 2003;347:1916-23.

\section{Journals scanned}

American Journal of Medicine; American Journal of Physiology: Heart and Circulatory Physiology; Annals of Emergency Medicine; Annals of Thoracic Surgery; Archives of Internal Medicine; BM; Chest; European Journal of Cardiothoracic Surgery; Lancet; JAMA; Journal of Clinical Investigation; Journal of Diabetes and its Complications; Journal of Immunology; Journal of Thoracic and Cardiovascular Surgery; Nature Medicine; New England Journal of Medicine; Pharmacoeconomics; Thorax

\section{Reviewers}

Dr Oliver Segal, Dr Tom Wong, Dr Vias Markides, Dr Diana Gorog, Dr Akhil Kapur, Dr Andrew Sharp, Dr Pipin Ko 